\title{
الإبداع اللوني ودوره في التوجيn داخل المباني التعليمية وفقَا لمبدأ التمهيم الشامل Color Creativity and its role in the Guidance of Ëducational Buildings in Accordance with the Principle of Universal Design
}

\section{المدرس المساعد بكلية الفنون الجميلة- جامعة فاروس بالإسكندرية

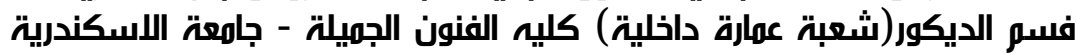

الالسـر: غادة محهود احمد السيد Ghada.elsaid@pua.edu.eg

التصميم الثامل للمدارس عادة يكون في بيئة يتشارك فيها الطلاب العاديين بذوي الإحتياجات الخاصة على وجاه

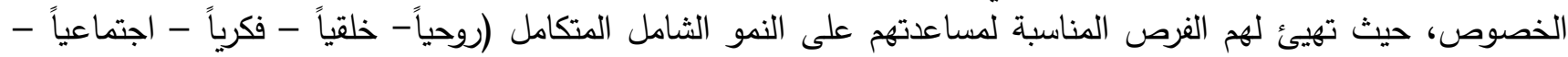

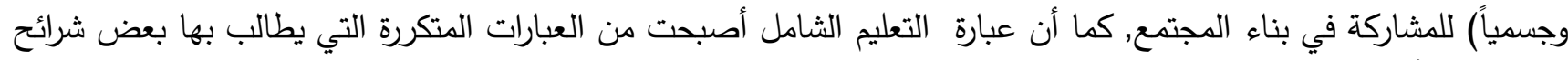

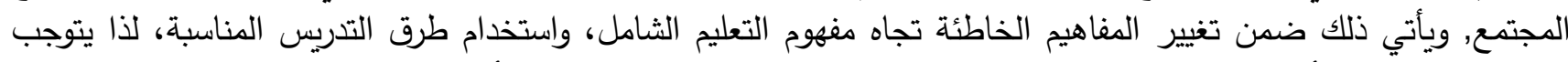
علينا كمجتمع واعي أن نعرف ماذا يعني التعليم الثامل وما هي مبادئه لتطبيقه في منشأتنا التعليمية على الوجه التهاه الصحيح. إن الهدف من تصميم المدارس الثاملة يأتي لتغيير المفاهيم تجاه مفهوم التعليم الثامل، وهو دمج الطلاب المعاقين

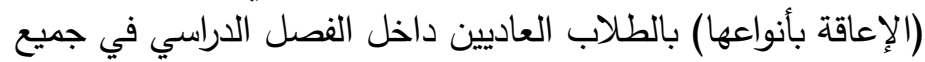

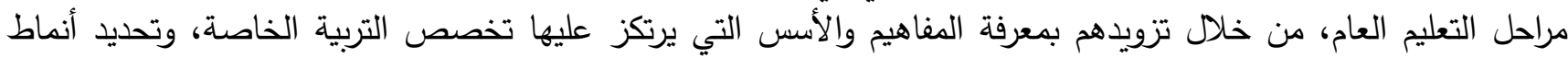

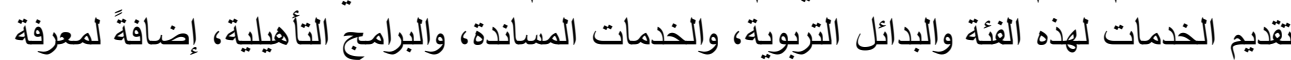

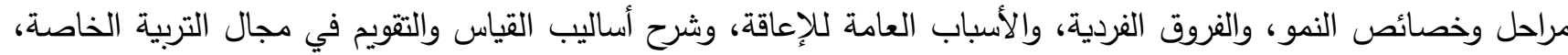
واستخدام طرق التدريس المناسبة، وتصميم البرامج السلوكية، وتطبيق استراتيجيات تتمية المهارات الاستقلالية لذوي الاحتياجات

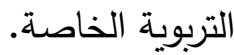

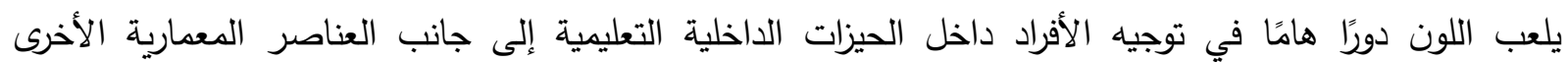

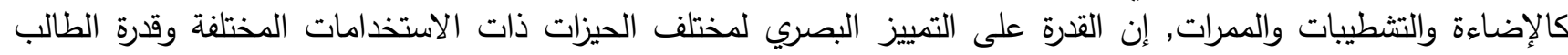
على التجول باستقلالية هو الهدف الأساسي للتصميم لذا يجب تهيئة بيئة العمل المدرسية كي تفي باحتياجات الطلاب وتتفهم يفيد الاختيار الجيد للون في عمل الاكواد اللونية الخاصة بعملية التوجيه واختيار التباين اللوني المناسب لمحددات

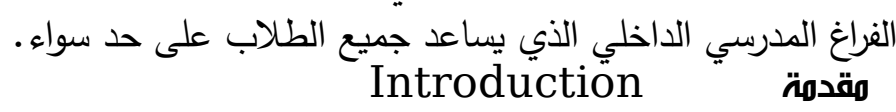
مقدرتهم.

كان

كان التصميم ولايزال هو نتاج التفاعل مع الإحتياجات الإنسانية التى تتوالد مع التعايش اليومى للدحددات الحياتية عبر

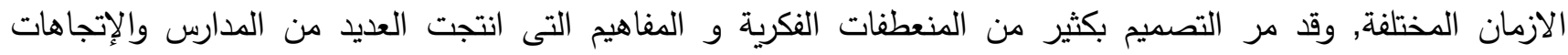

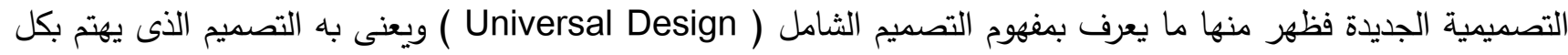
فئات المستخدمين لجميع المنتجات والبيئات.

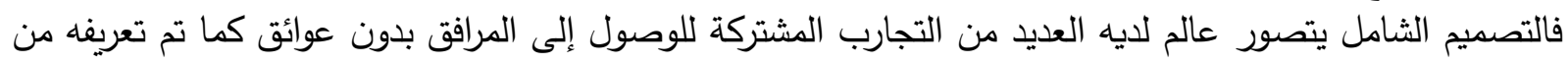

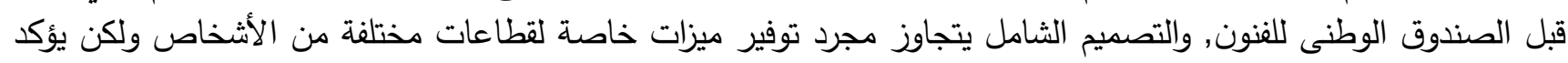

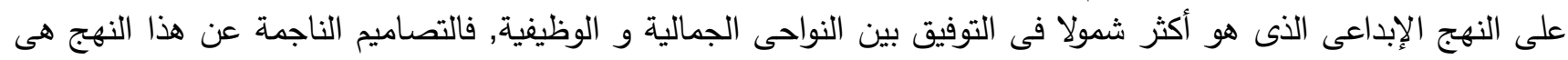

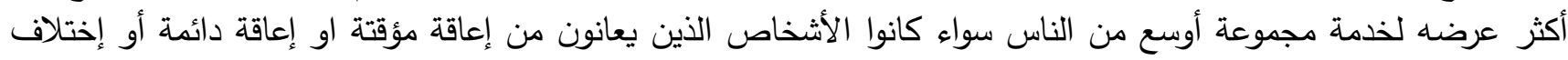

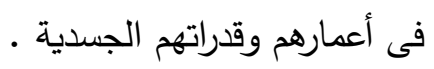
وقد قامت بعض الدول بتطبيق التصميم الثامل فى الفراغات التعليمية بالتعاون مع أعرق الجامعات المرتمـة بالتربية

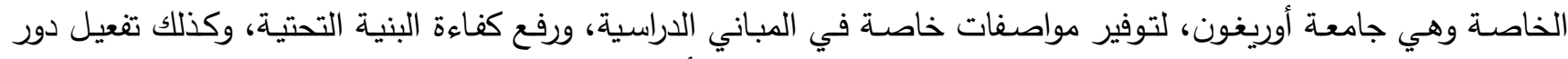

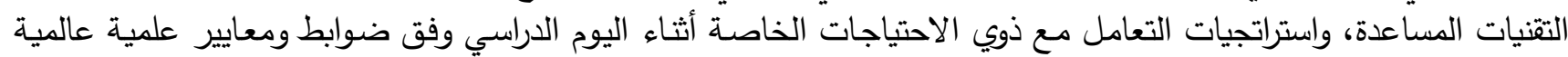

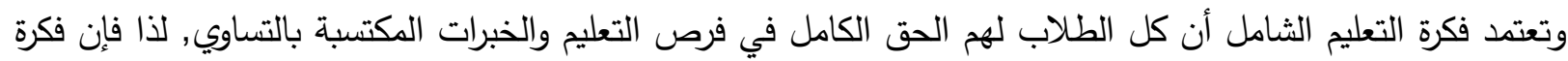

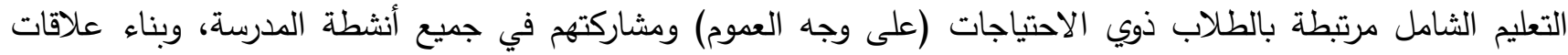
اجتماعية وصداقات تدفعهم إلى الأمام.

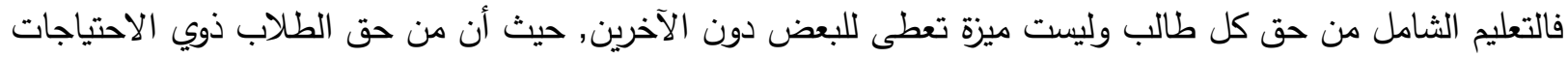

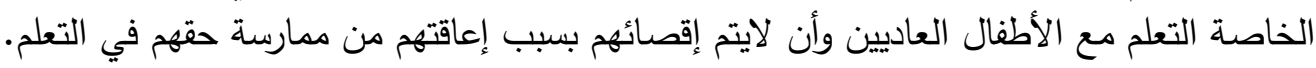




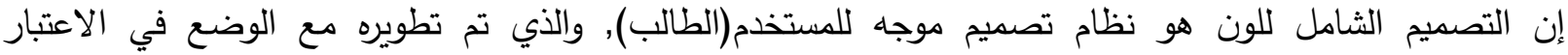

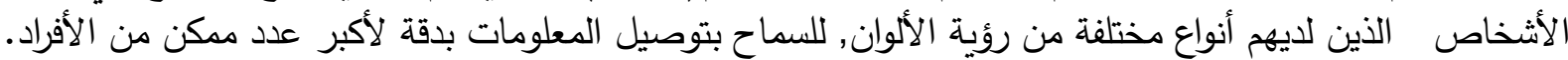

\section{Statement Of The Problem}

في العصر الحالي معظم عمليات التخطيط والتصميم الداخلى تعتمد في حلولها لمشكلات الفراغات علي معالجات

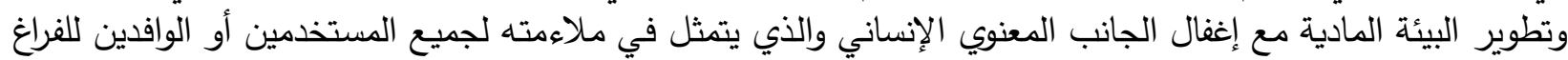

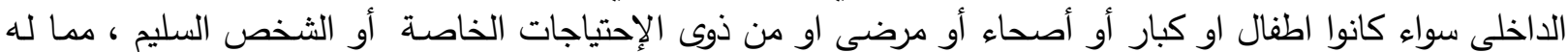

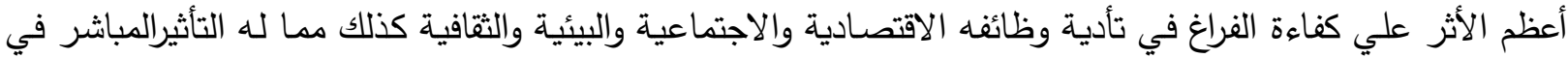
وظائف وجماليات البيئة المبنية. غالبا ما يتم تطبيق إمكانية وسهولة الوصول للأماكن فقط عن طريقة لونيات لوحات إرشادية مع إغفال الجانب التصميمي اللوني كوسيلة للتوجيه داخل المباني التعليمية. إغفال تأثيرالتصميم اللوني الثامل في التياني التعليم الثامل الإيجابي على الأفراد بحيث يتشارك الجميع الفرص والخبرات

\section{Significance Of The Study}

أهمية البحث

يعد مقياس تثييم مدى نجاح التصميم من عدمه هو مدى قدرة المصمم على تسهيل الوصول إلى العناصر الرئيسية في

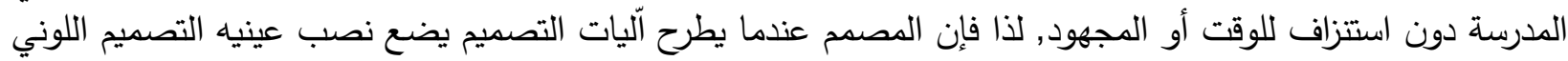
اللازم لتوجيه المستخدمين بداية من المدخل وحتى الوصول إلى النشاط الرئيسي المراد الوصول إليها

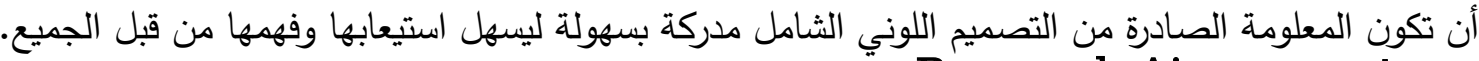

\section{Research Aim}

أهداف البحث

• تقوية العلاقة بين السلوك الثخصى للطلاب والتصميم الداخلى للمباني التعليمية من خلال اللون.

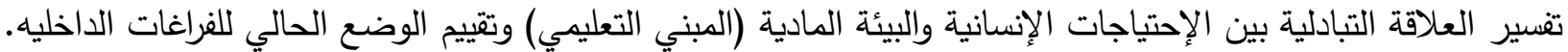

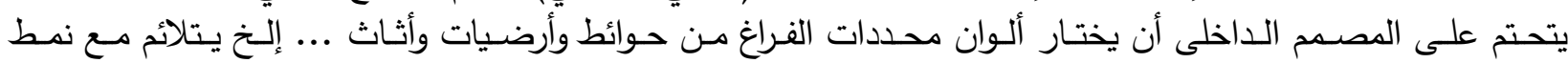

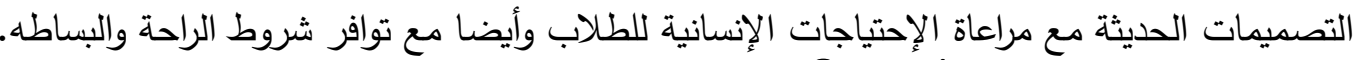

\section{Questions}

التساؤلات

هل توجد علاقه بين الإحتياجات الإنسانية و التصميم اللوني الداخلى؟ الإن

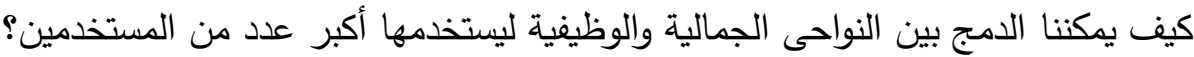

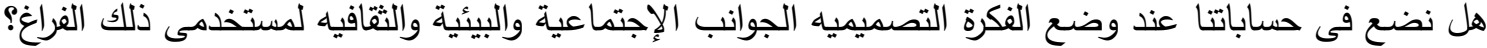

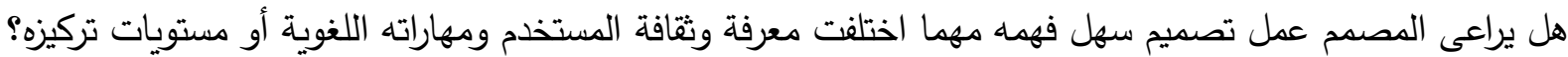

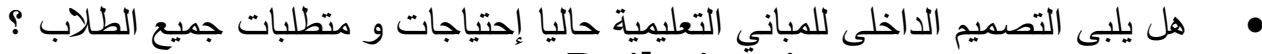
Deilmination

تتتاول الدراسة موضوع التصديم اللوني الثامل (Universal Color Design) وكيفية تطبيقه لتهيئة فراغ دراسي داخلى

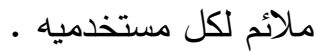

الحدود المكانية:

يختص البحث بدراسة وتحليل أنواع الحيزات الداخلية التعليمية المختلفة لتحقيق مبدأ التصميم الثامل.

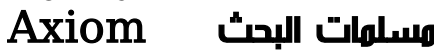
وجود علاقة تبادلية بين الإحتياجات الشخصية والفراغات الداخلية. إتخاذ القرارات التصميميه بثأن الفراغات الداخليه دون العتبات لإنات للاحتياجات الإجتماعيه والنفسيه والسلوكيه اللازمه لمستخدمى الفراغ. وجود قصور في الدراسات الإنسانية (الإحتياجات الثخصية) يعوق تأدية الفراغات الداخليه (البيئة المادية ) لوظائفها الجمالية والاقتصادية والاجتماعية والترفيهية والثقافية.

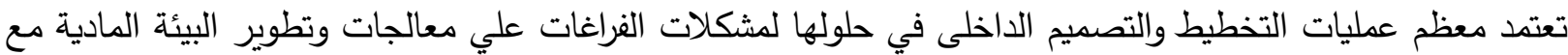
إغفال الجانب المعنوي الإنساني والذي يتمثل في الإحتياج الإنساني للأفراد المستخدمين أو الوافدين للفراغ الداخلى.

تقوم الدراسة على أساس المنهج الوصفي والتحليلى وتطبيقه لتحسين أداء الفراغ الداخلى وتجهيزه وتطبيق مبادئ التصميم 
وهو منهج من المناهج العلمية فى الدراسة البحثية ويقوم على اتباع خطوات منظمه لمعالجة الظواهر والقضايا كما أنه نمط من

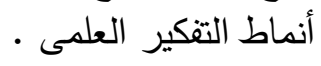
وقد تم إتباع هذا المنهج لإنه علميا يستخدم فى وصف الظواهر الإنسانيه الإجتماعية للوقوف على أسبابها, وقيمتها, والعوامل التى تحكم فى وجودها, وأهميتها.

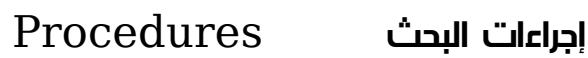

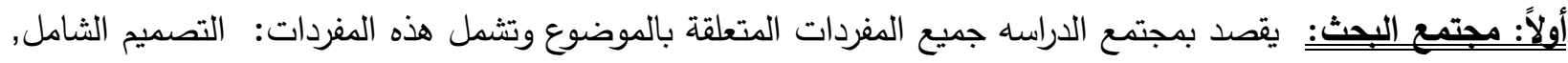

$$
\text { • }
$$

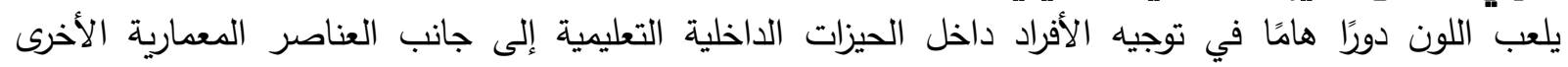

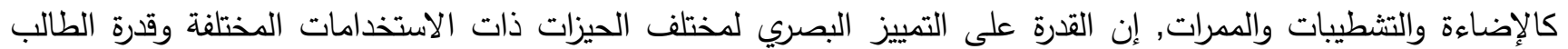
على التجول باستقلالية هو الهدف الأساسي للتصميم لذا يجب تهيئة بيئة العمل المدرسية كي تفي باحتياجات الطلاب وتتفهم مقدرتهم. يفيد الاختيار الجيد للون في عمل الاكواد اللونية الخاصة بعملية التوجيه واختيار التباين اللوني المناسب لمحددات

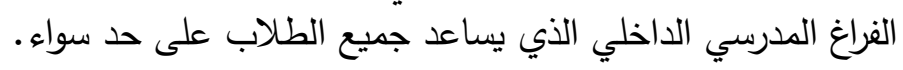

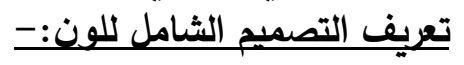

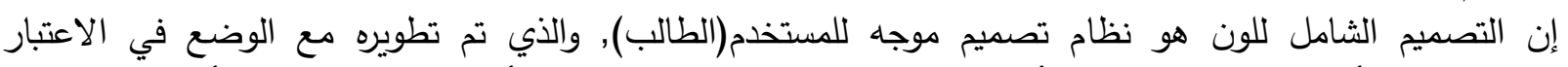

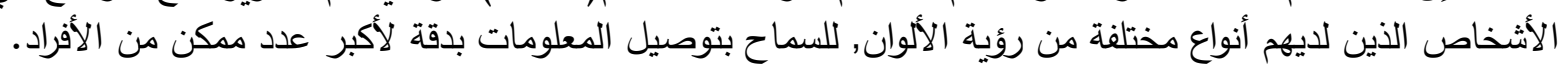

\section{أهمية التمهيم اللوني الشامل للحيزات التعليمية:-}

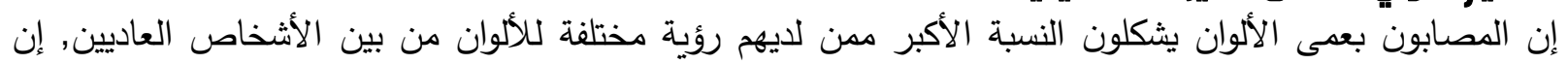

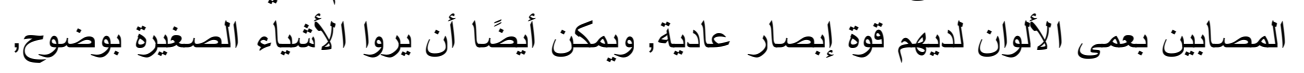

ولكن بالنسبة لأمزجة معينة من الألوان تكون لديهج رؤية مختلفة عن الرؤية الثائعة.

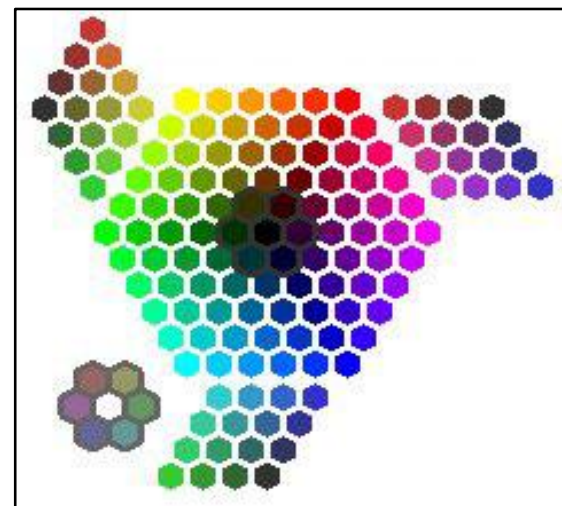

الرؤية الطبيعية للألوان

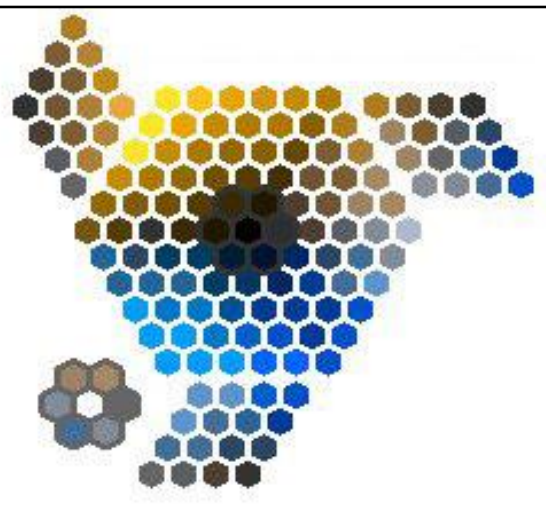

رؤيسة اللون عند مرضى عمى الألوان (1)

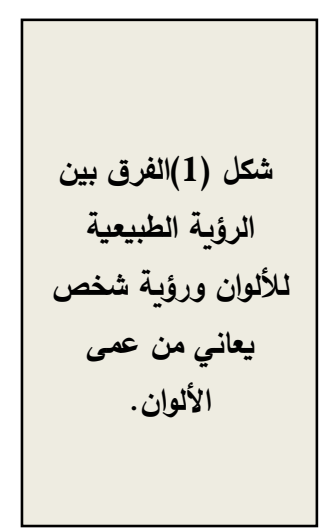

شكل (1)(الفرق بين الرؤية الطبيعية للألوان ورؤية شخص يعاني من عدى الألوان.

إضافة إلى هذا, هناك الآلاف من الأشخاص الذين لا يمكنهم التمييز بين أي ألوان ويمكنه معرفة الفرق بين الألوان فقط من

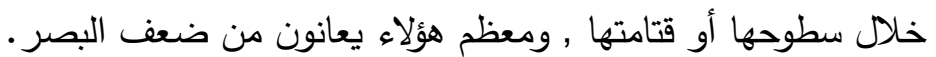

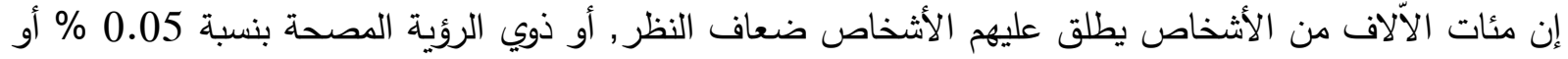

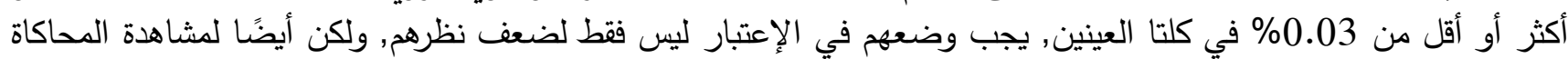
التي يرونها ودرجات التباين. 
إن الهدف من التصميم الثامل للون هو وضع المصابون بعمى الألوان في الإعتبار وإعادة الفحص الكامل لإجراء

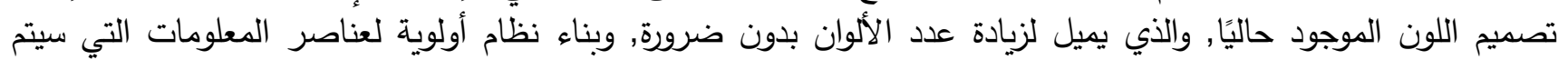

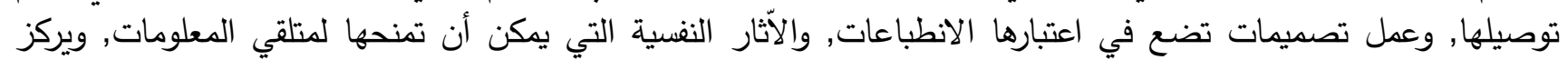

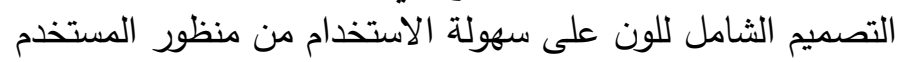

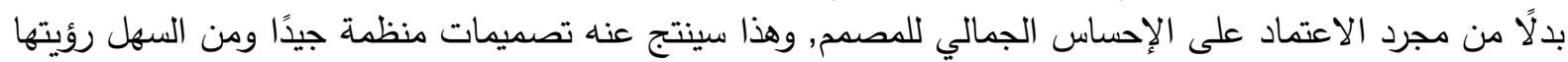

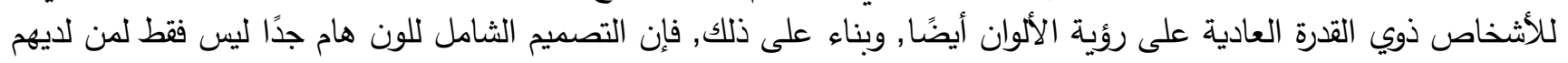
عمى ألوان ولكن للجميع.

هناك أنواع عديدة من برامج المحاكاة التي تم إطلاقها لمحاكاة المشاهد التي يراها الأشخاص المصابون بعمى الألوان, وهذه المانه

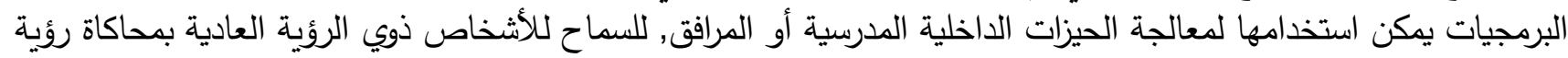
المصابين بعمى الألمان.

التأثيرات الفسيولوجية السيكولوجية للألوان على مستخدميا المبنى التعليميا:-

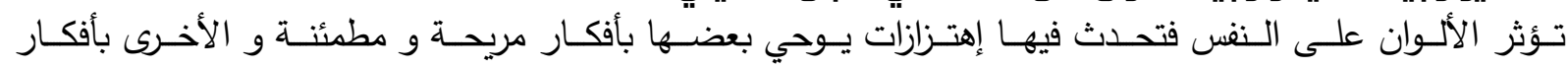

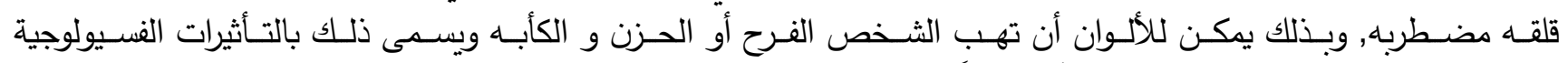

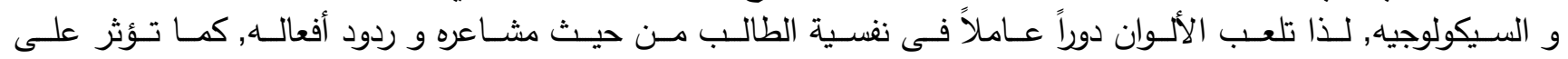

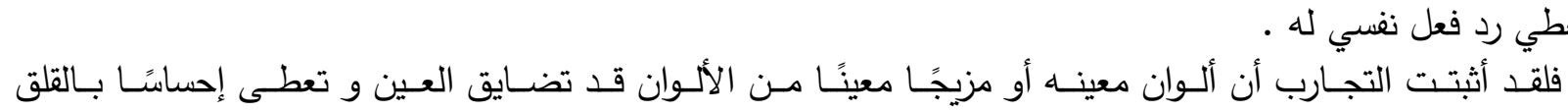

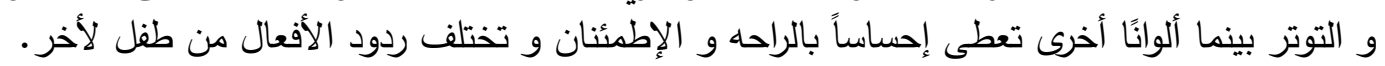

\section{تأثثر لون الحيزات الداخلية على الإدراك الحسي للفرد:}

يسـاهم اللـون فـي إعطـاء الثـعور بصــر أو إتسـاع الحيـز أو بزيـادة الطـول أو العـرض للحسائط أو بإنخفـاض أو إرتفــاع السقف. يجب الإحتراس من اختيار لون الممرات فإن اختيار ألوان قاتمة يعطي الثعور بضيق الممر.

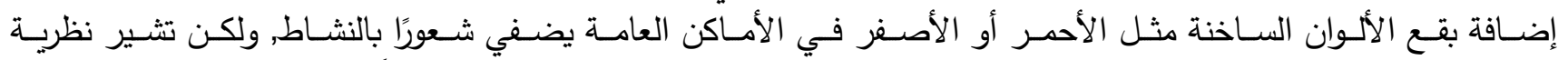

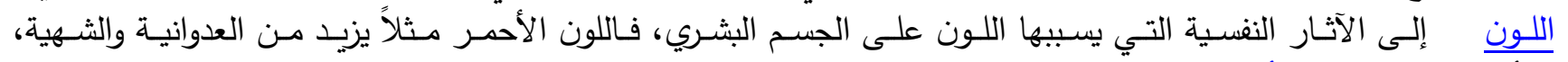

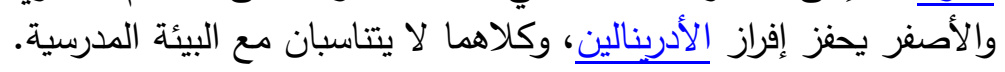

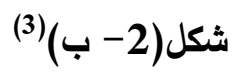

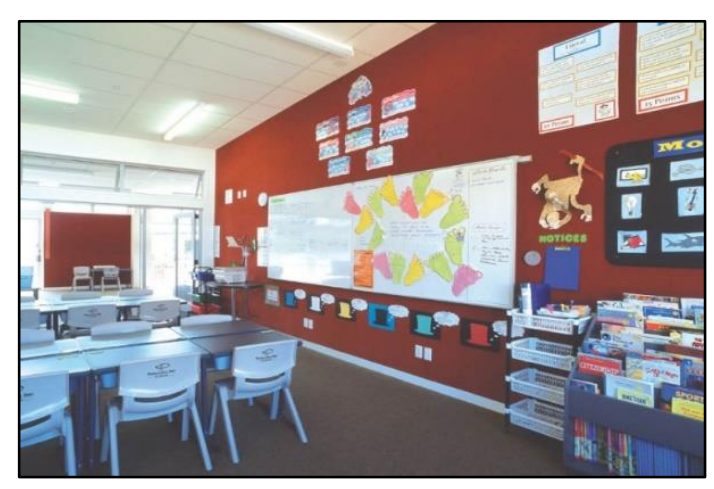

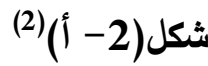

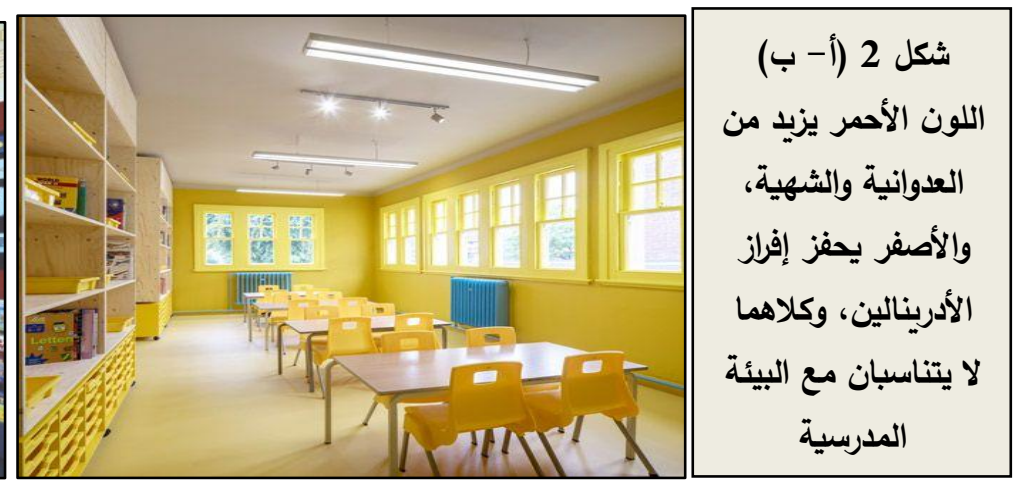

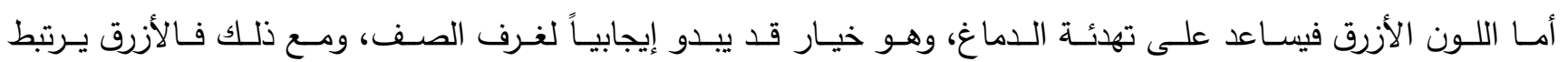

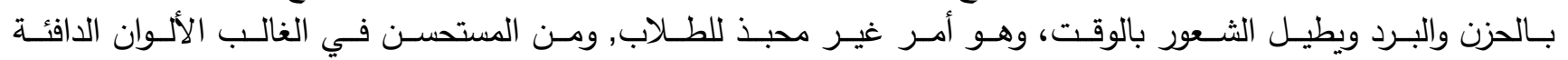

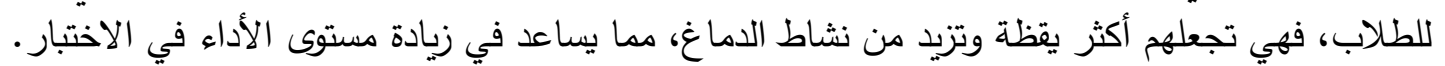

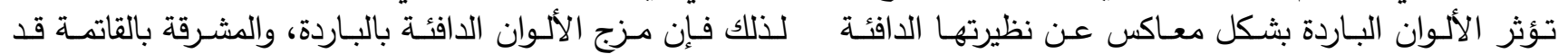

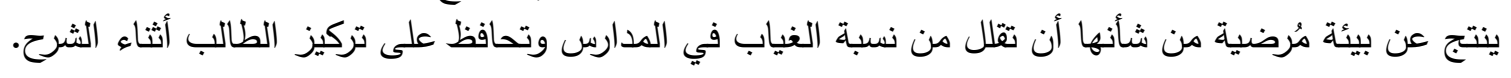

2 -https://www.pinterest.com/ pin/293578469444056950/

3 -http://www.krameducation.com.au/images/Wall\%20Carpet\%20Classroom.jpg 

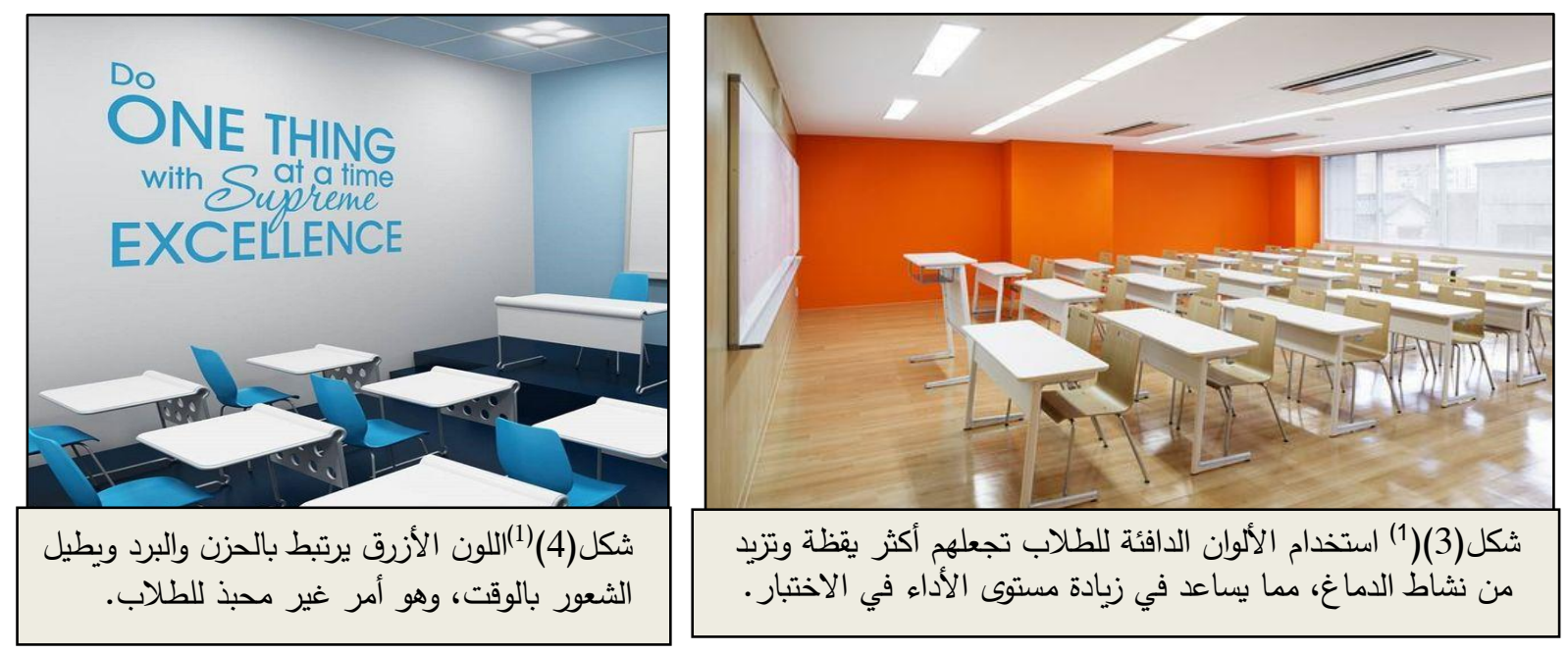

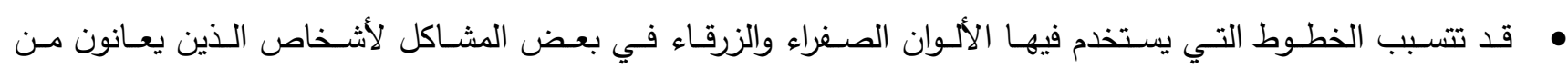

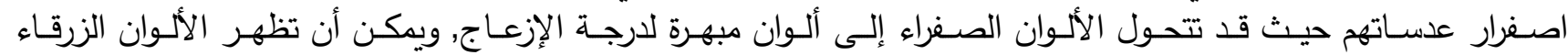

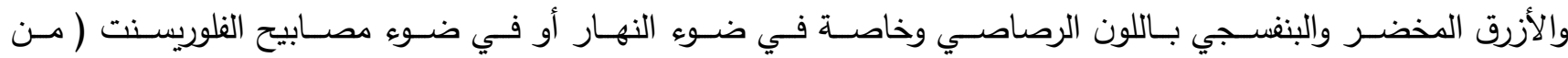

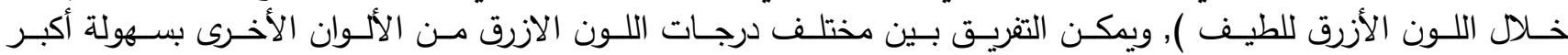

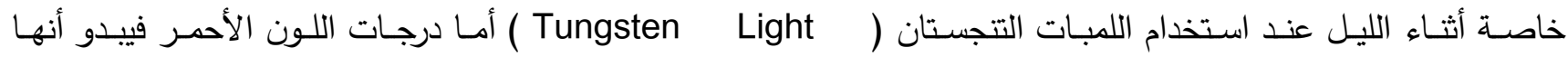

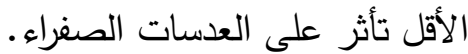

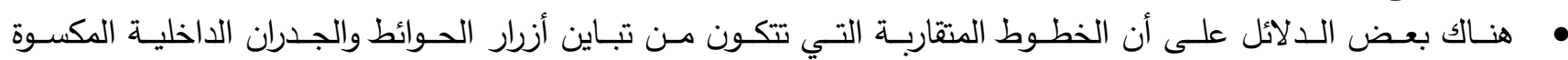

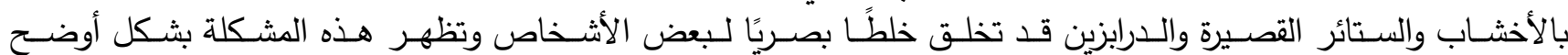

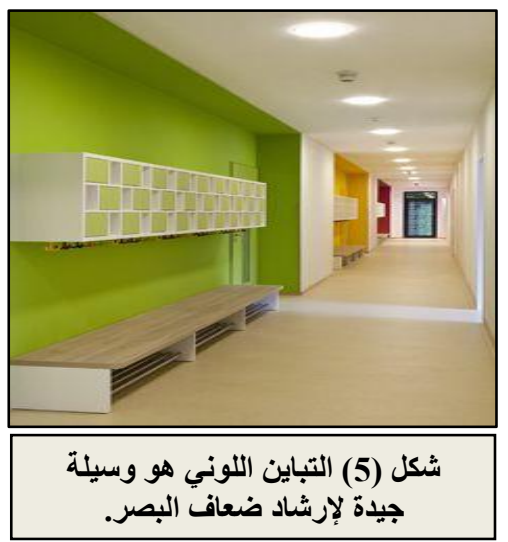

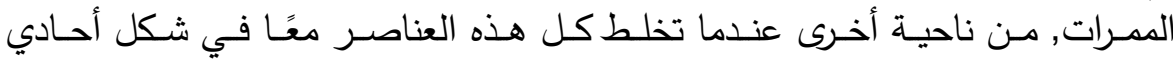

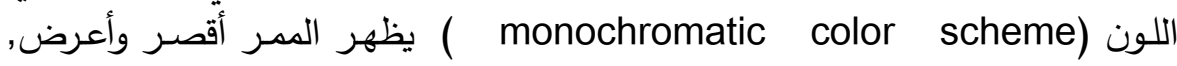

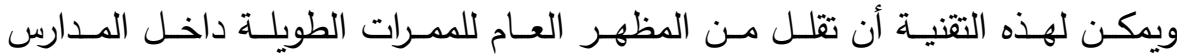

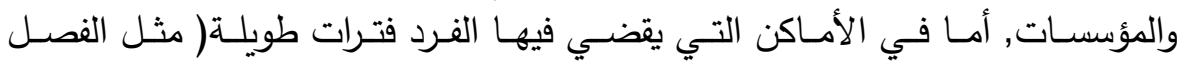

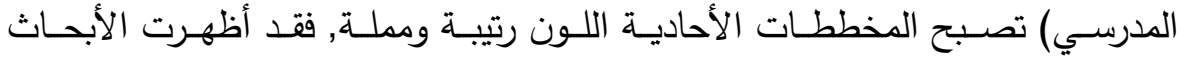

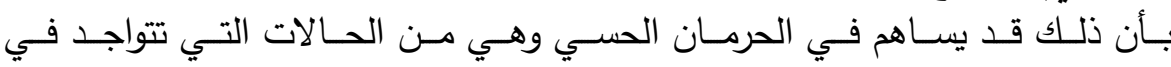

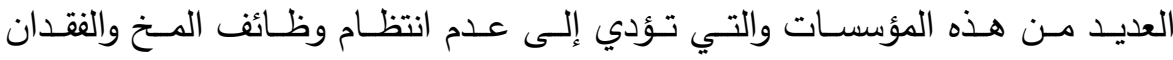

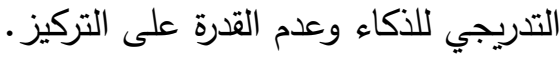

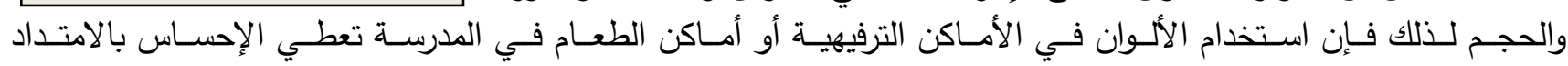

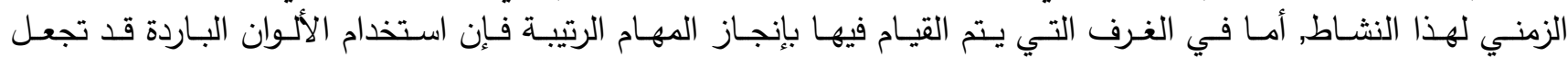
الإحساس بمرور الوقت أسرع.

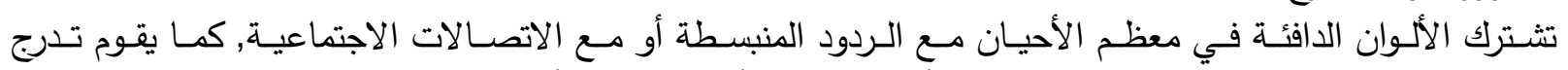

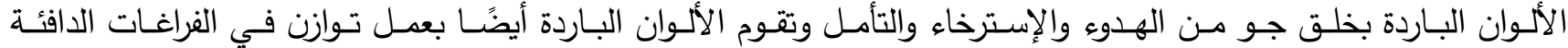

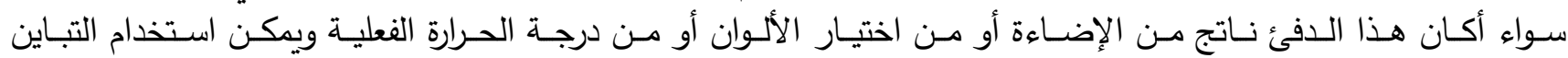
في الألوان لخلق حالات حسية متتوعة. تأثير ضعف الإبصار على الرؤية الواضحة حلية للونة:

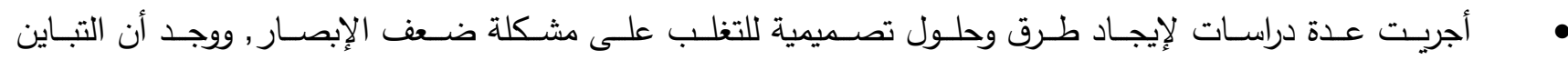

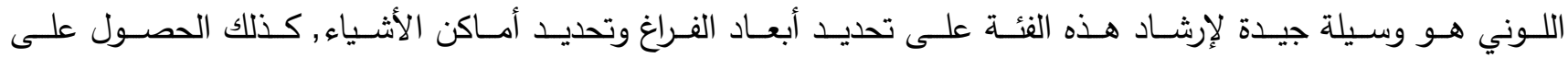
الإستقلالية في التنقل. 


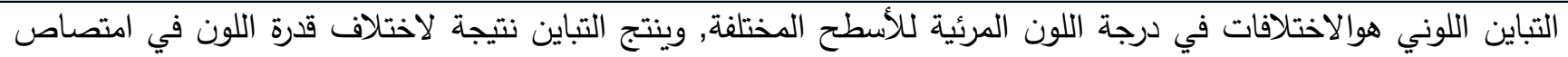

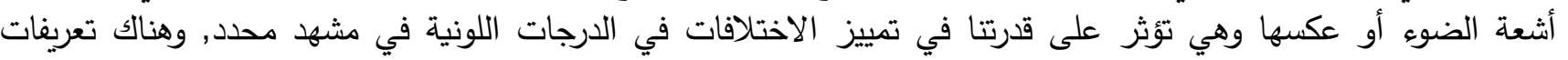

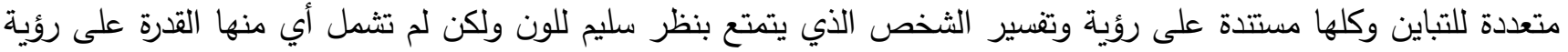
اللون لثخص يعاني من إعاقة بصرية. وقد استتدت ابحاث شملت عدد كبير من الأشخاص من ضمنهم أفراد يعانون من ضعف الإبصار والتي تتطلب

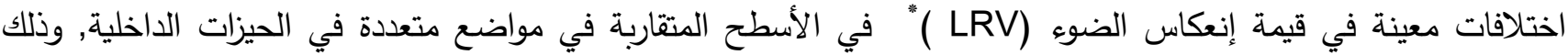

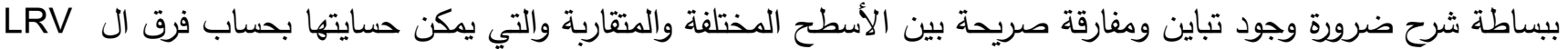

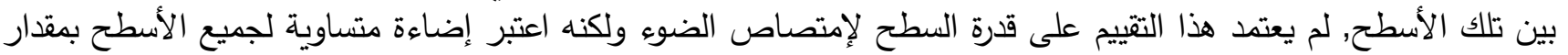
Lux 100 أو أكثر , الأسطح التي ترى سوية مثل الباب أو إطار الباب أو التي تقترب من بعضها مثل الدرابزين والحائط

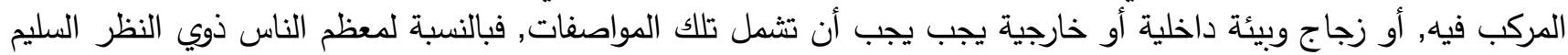
يظهر التباين بين الألوان عن طريق الاختلاف بين طبئنة دارجة فيعة الألوان (وتدرجها) أو شدة الألوان (كثافتها).

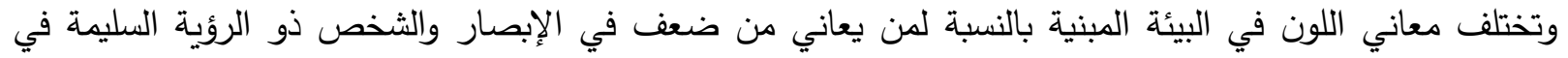

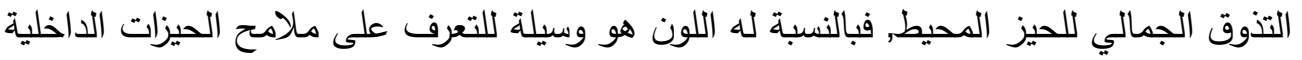
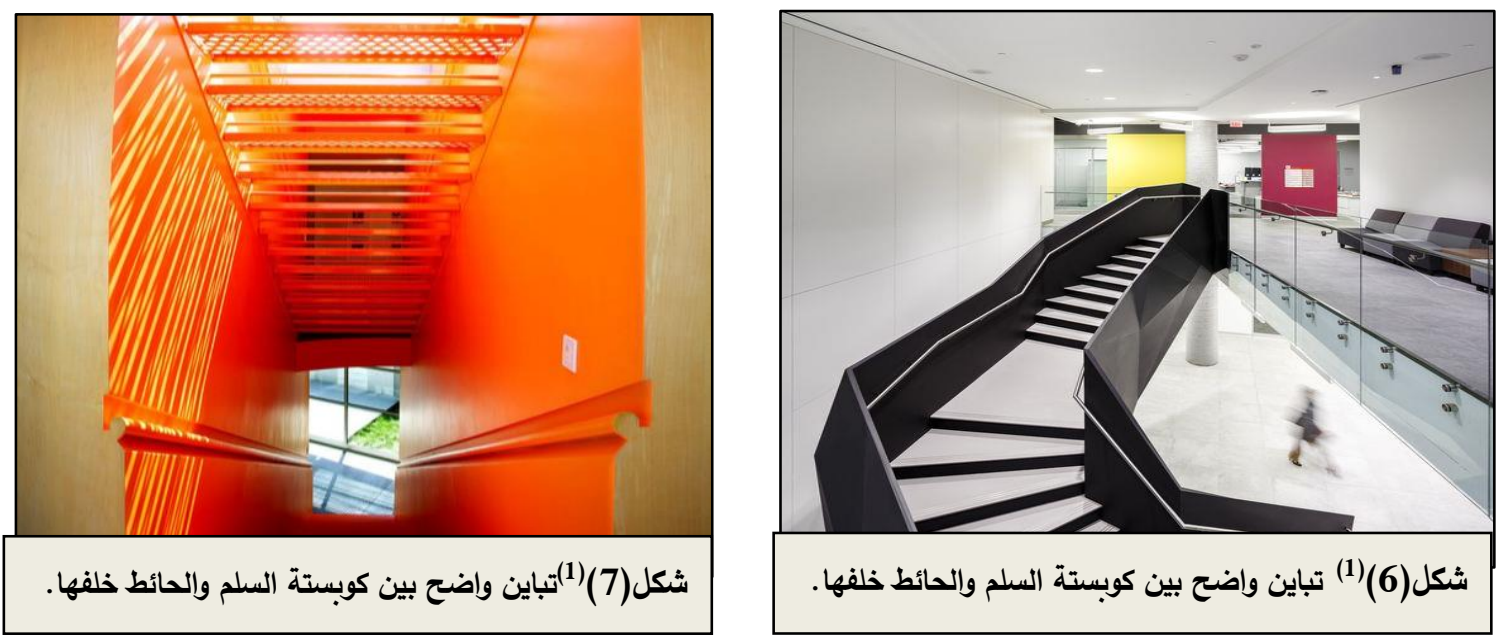

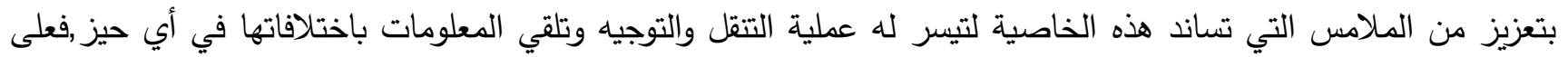

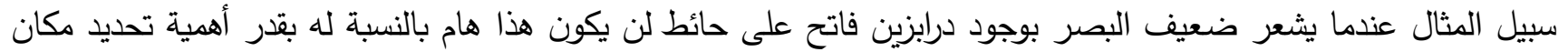

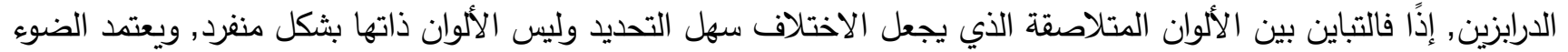

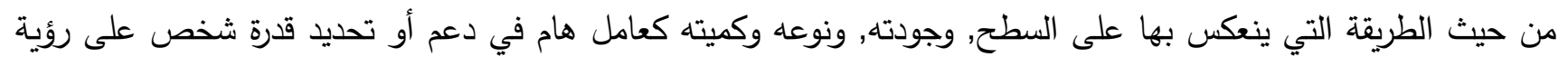

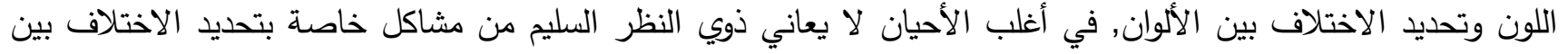
الألوان حتى في ظرف وتح إضاءة مختلفة. لا يعتمد ذوي الإعاقة البصرية على درجة صبغة اللون ونقاء اللون ودرجة الإشباع وقدرته على عكس الإضاءة

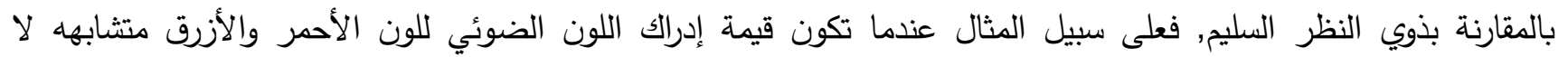

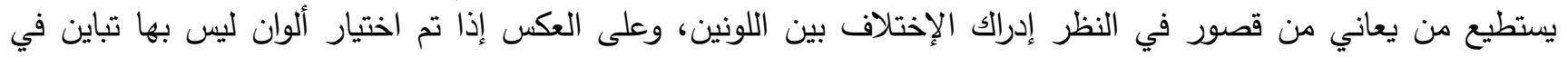
التدرج مثل الرمادي الفاتح والغامق لن يستطيع أيًا من أصحاب النظر السليم أو من يعاني من إعاقة بصرية من تحديد النيان الاختلاف بينهما. إذًا لكل لون مقاييس خاصة به (LRV) يمكن الحصول على هذه القيمة لأي منتج يمكن استخدامه في التصميم

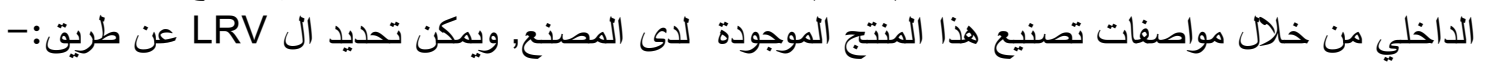
المقارنات البصرية أو الظاهرية.

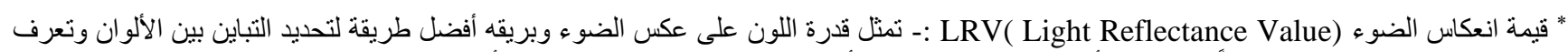
هذه القدرة بقيمة انعكاس الضوء طبقًا لمقياس يبدأ من صفر لسطح ماص (أسود حاللك) إلى 100 لسطح عاكس(أبيض ناصع). 
قياس LRV للون باستخدام المقياس اللوني أو مقياس الإنعكاس بالمقارنة البصرية, رغم إنها طريقة غير دقيقة للقياس إلا إنها

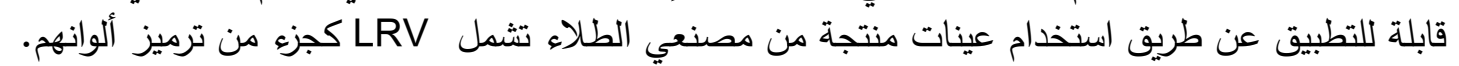

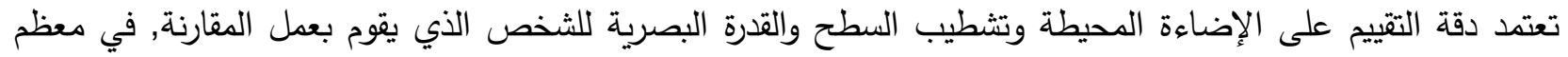

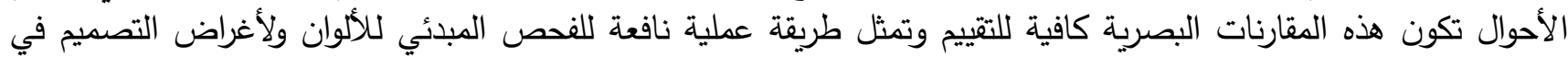

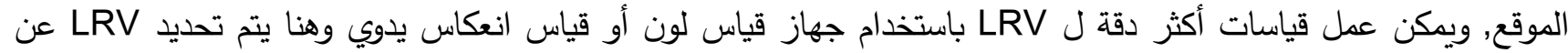
طريق قياس قيمة الإنعكاس لسطح

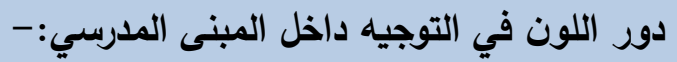

يعتبر اللون من العوامل المفيدة في تصميم عملية التعرف على الطريق (التوجيه). ويعمل اللون دور المساعد في عملية

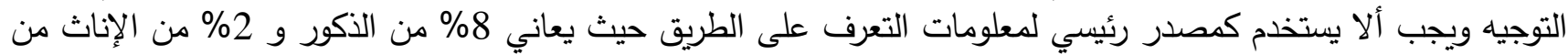
أمراض تؤثر على قدرتهم على تمييز الألوان.

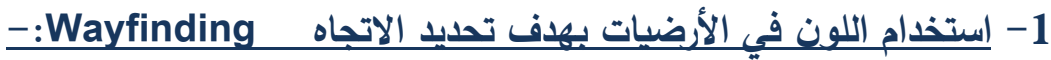

تعد الألوان من الأدوات المساعدة ونظام جيد للتواصل اللغوي فيمكن الإعتماد عليها للتمييز بين الأجزاء المختلفة للمدرسة.

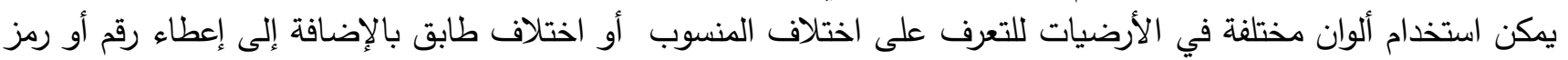
معين لكل طابق. تساعد الألوان على تثبيت المعلومة في ذهن المستخدم على ألا يكون اللون لازمًا لفهم كيفية تنظيم المبنى التعليمي.

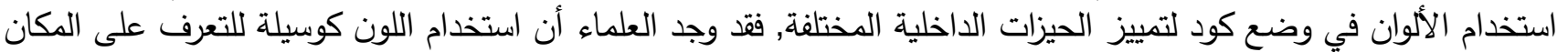

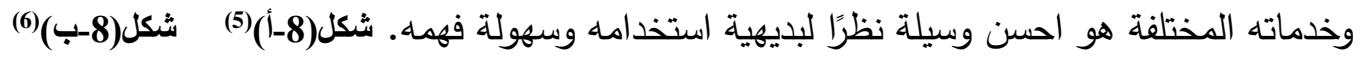
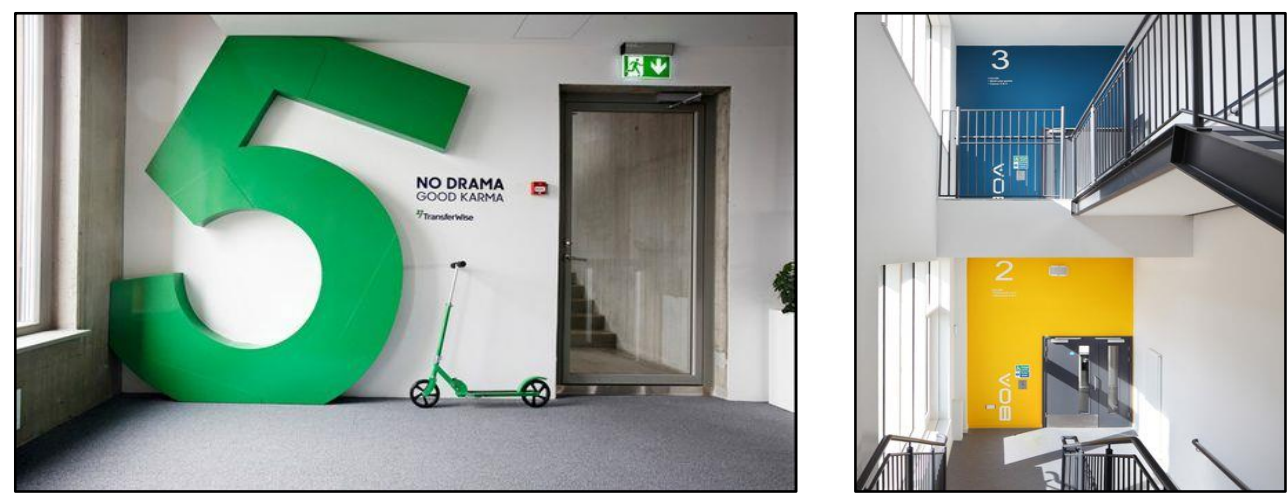

شكل 8 (أ-ب) تستخدم الألوان فى عملية التعرف العامة بالمكان لكن يجب مراعاة وجود من يعانى من عمى الألوان.

كما يمكن زيادة درجة الإهتداء إلى الطريق والتوجيه عن طريق تشطيبات الأرضيات, إن الاختلاف في اللون والنقش يساعد الإدات

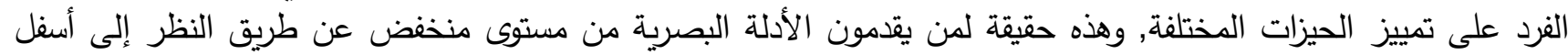

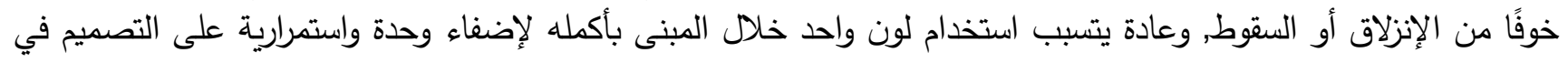

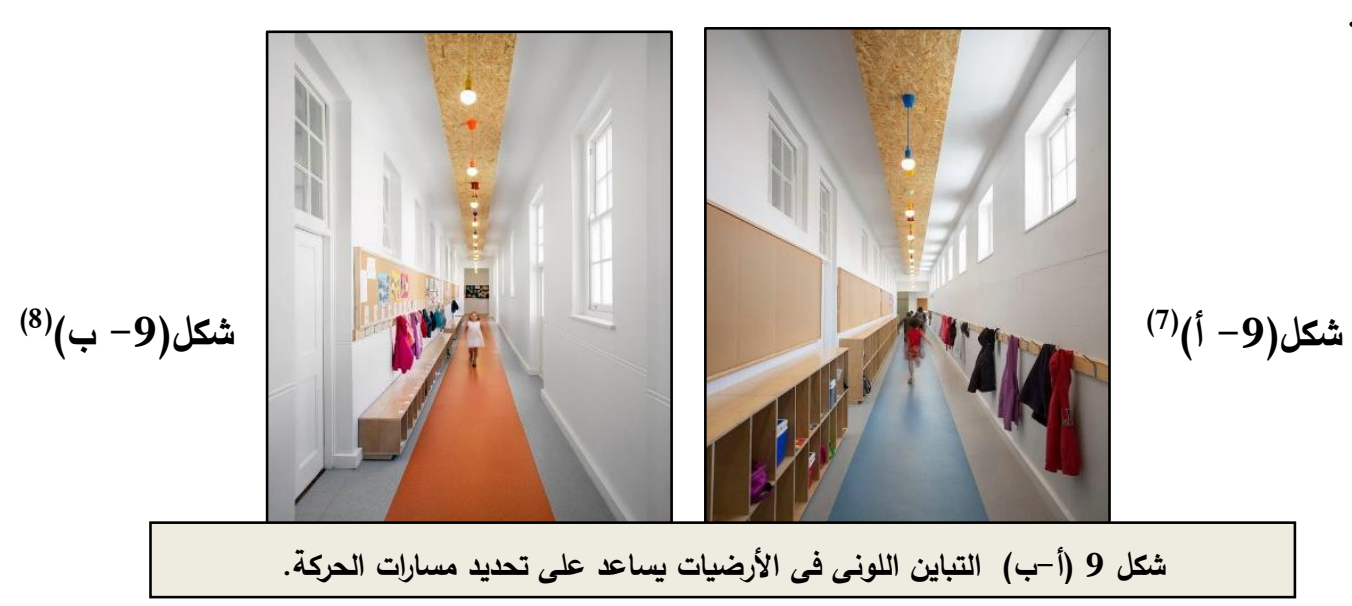

صعوبة التوجيه. 


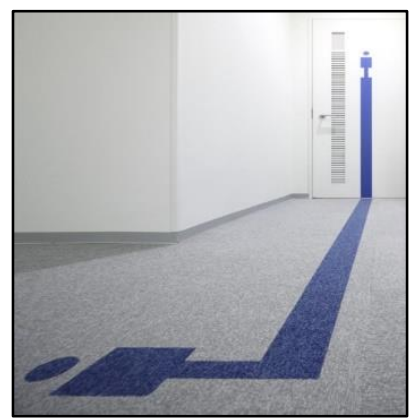

شكل(10) ب(10)

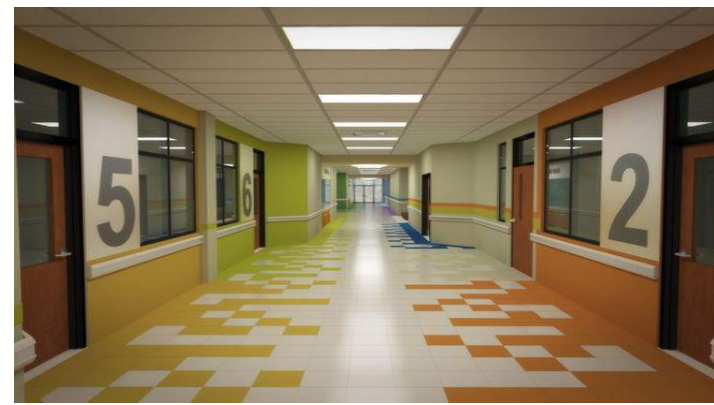

شكل(10) - (1)

شكل 10 (أ-ب) استخدام أرضيات من لون متباين بإمتداد ممر السير فى محور الممر.

لمساعدة من يعانون من ضعف الإبصار عل الإهتداء إلى الطريق تستخدم شرائط متباينة اللون مع الأرضية على جوانب الممر مع استخدام أرضيات من لون منباين بإمتداد ممر السير في محور المدر.

\section{دور الالون في التوبيه داخل المنى المدربي:}
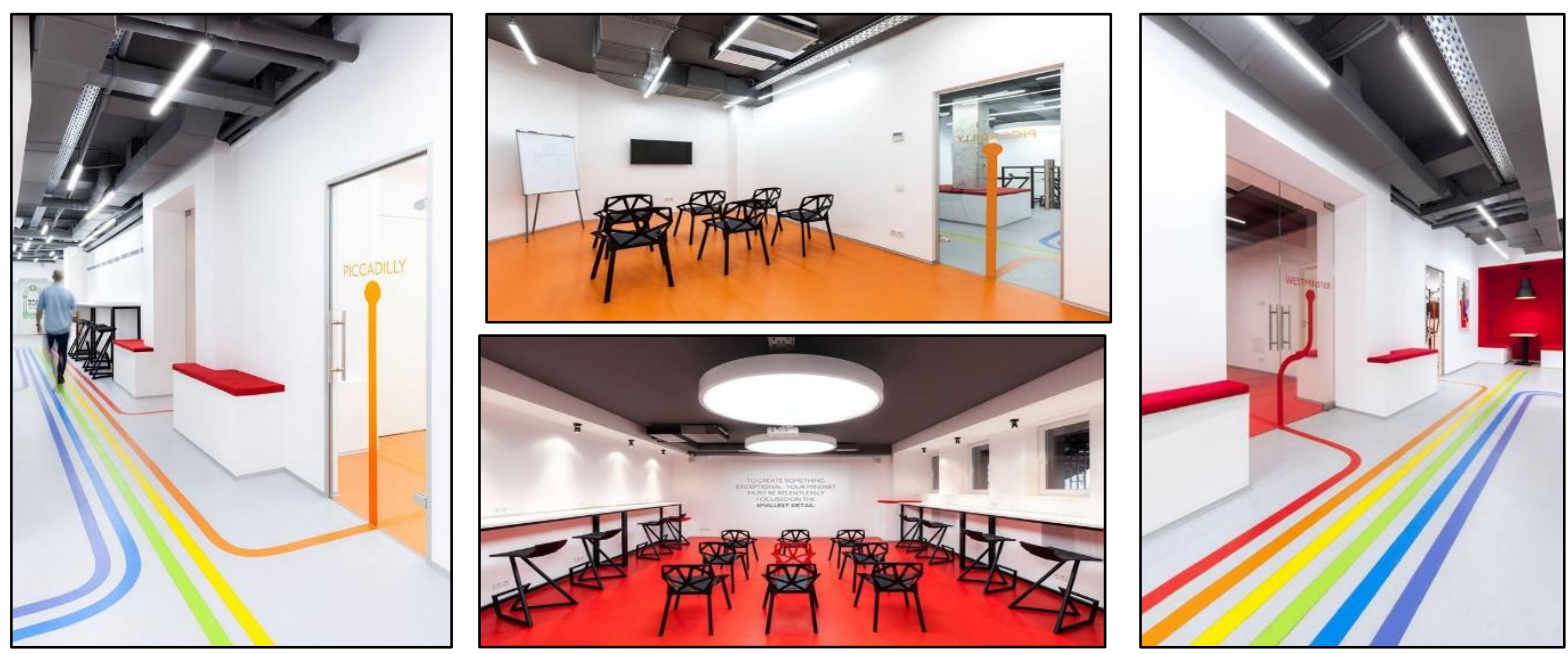

استخدام خطوط ملونة على الأرض مستوحاة من مترو أنفاق لندن تقود إلى الفصول الدراسية في المدرسة, وقد استخذمت ألوان قوس قزح على الأرض مع كتابة أسماء المحطات وكل خط يقود إلى الفصل الدراسي - مدرسة وندرهوب للغات, أوكرانيا (تصميم : المهنس المعماري إميل درويش).

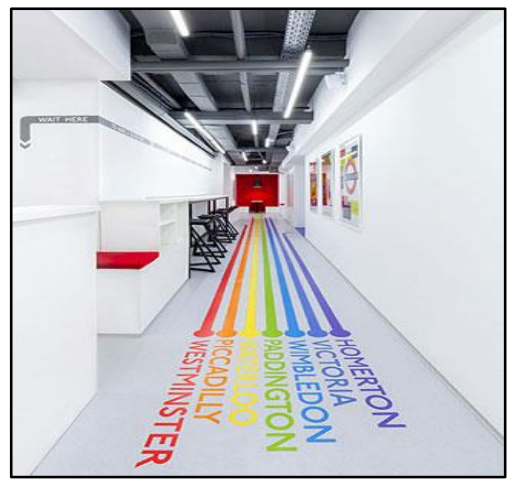

كتابة أسماء المحطات على كل خط على ألى الأرضية وهي تمثل أسماء الفصول الداسية.
خطوط قوس قزح الملونة على الأرض تقود إلى الفصول

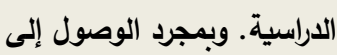

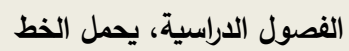
على الباب، ومرة واحدة يكون

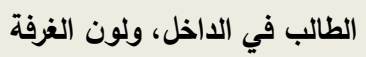
يتوافق مع الخط الذي يتبعه الطالب, وفي كل فصل دراسي، يوجد عمل فني مؤطر يمثل اسم الغرفة.

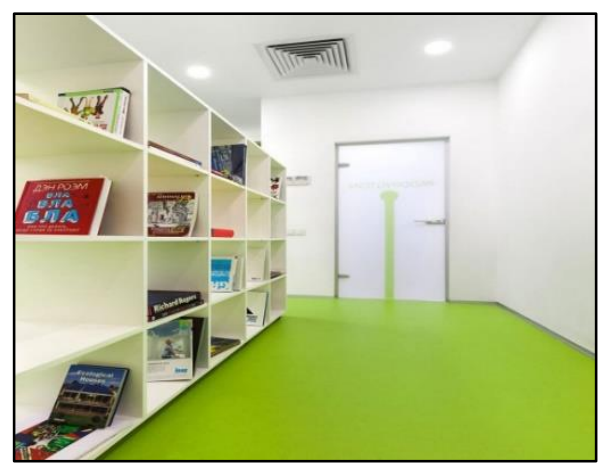

لون الغرفة يتوافق مع لون الخط المتبع من الممر 
التصميم الشامل للحيزات الداخلية ينصف الجميع وهذا يعني استخدام متساوي لجميع الوسائل المستخدمة مع توافر الخصوصية والسلامة والأمن والراحة فيها, كما يجب أن يوفر التصميم جميع المعلومات الأساسية من خلاعل المان أساليب متغيرة

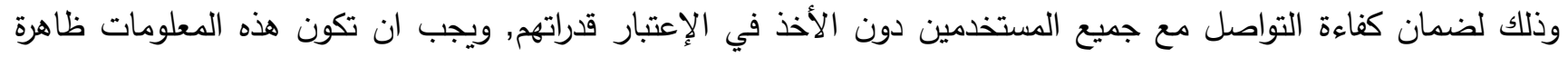

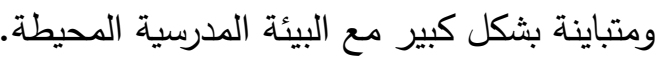

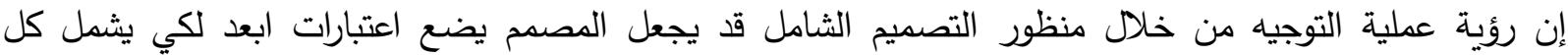

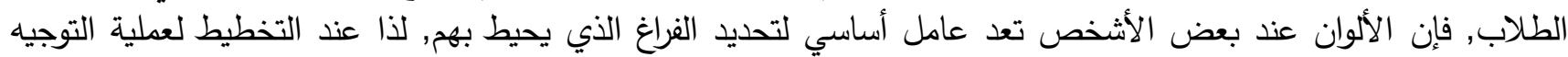
يجب أن يدرك المصمم الفوارق البشرية كي يؤدي الرسالة كاملة تخاطب كل المستخدمين وتفهم متطلباتهم واحتياجاتهم.

1- إيمان صلاح الدين حمزة الجميعي ـ " متطلبات التصميم الفر اغي لذوي الإحتباجات الخاصة ". رسالة ماجستير , جامعة عين شمس , كلية الهندسة , قسم العمارة , 2009.

2- داليا مصطفى عبدالسلام يونس. " تأثير مفهوم التصميم الثامل على تطور الفكر التصميمي للمتاحف " ". رسالة دكتوراه . جامعة الإسكندرية، كلية الفنون الجميلة , 2014.

1- Kneith B, and Geoffery c,"The Colour, Light and Contrast manual", Willey-Blackwell, United Kingdom, 2010.

2- M.Powell Lawell , " Designing By Degree assing and incorporating individual Accessibility needs " froom, Wolfgang. F and Ostroff.E " Universal design handbook " .chapter7,Mc Graw-hill.2001. 3- Pallasmaa,Juhani.The ayes of the skin: Architecture and the Senses. Hoboken, Nj: Wiley, 